\title{
Answer to the Topic "Management of Pyogenic Discitis"
}

\author{
Pramod Devkota ${ }^{1}$, Krishnakumar $\mathrm{R}^{2}$, Renjith Kumar J ${ }^{2}$ \\ ${ }^{1}$ Department of Orthopaedics and Trauma Surgery, Gandaki Medical College Teaching Hospital, Pokhara, Nepal \\ ${ }^{2}$ Division of Spine and Musculoskeletal Oncology, Department of Orthopaedics and Trauma Surgery, \\ Amrita Institute of Medical Sciences, Kerala, India
}

Sir/Madam,

We thank Beuy Joob for commenting on our recent report on "Surgical Management of Pyogenic Discitis of Lumbar Region [1]." We were able to get 100\% culture positivity in the 42 cases probably because of open surgical extensive debridement of the disc space during posterior lumbar interbody fusion. Discitis due to tuberculosis (TB) and other causes were excluded, and only those that are managed surgically were included. The clinically and histopathologically confirmed TB discitis were not included.

We also did histopathological analysis of the infected materials in all cases, which showed evidence of acute infection without granuloma formation. Obtaining proper representative sample for culture is of paramount importance in getting positive result. In case of culture negativity, simultaneous histopathological analysis of the material could help the clinician in differentiating pyogenic discitis from tuberculous discitis by the absence of granuloma. So, the tissue specimens should be subjected to histological analysis as well. It is even more important in tropical regions to diagnose and treat pyogenic discitis from $\mathrm{TB}$, to avoid the major complications due to long term empirical anti-tuberculous drug therapy.

\section{Conflict of Interest}

No potential conflict of interest relevant to this article was reported.

\section{References}

1. Devkota P, Krishnakumar R, Renjith Kumar J. Surgical management of pyogenic discitis of lumbar region. Asian Spine J 2014;8:177-82.

Received May 7, 2014; Revised May 7, 2014; Accepted May 7, 2014

Corresponding author: Pramod Devkota

Department of Orthopaedic and Trauma Surgery Gandaki Medical College Teaching Hospital

Sanchayakosh Bhawan, Naya Bazaar, Pokhara, Nepal

Tel: +97761-538595, Fax: +97761-550254, E-mail: pramodcd@yahoo.com 